\title{
MERANCANG SISTEM PENGOLAHAN ATK BERBASIS WEB PADA PT. ARTHAASIA FINANCE
}

\author{
Muhamad Zahruddin ${ }^{1}$ \\ Indri Handayani \\ Nini Santika ${ }^{3}$ \\ Dosen Jurusan Sistem Informasi STMIK Raharja ${ }^{1}$ \\ Dosen Jurusan Sistem Informasi STMIK Raharja ${ }^{2}$ \\ Mahasiswa STMIK Raharja Jurusan Sistem Informasi ${ }^{3}$ \\ Jl. Jendral Sudriman No. 40, Modern Cikokol Kota Tangerang \\ Email : zahruddin@ raharja.info' ${ }^{1}$,indri@ raharja.info ${ }^{2}$, nini@ raharja.info ${ }^{3}$
}

Diterima: 4 Juli 2018/ Disetujui : 2 Juli 2018

\begin{abstract}
PT. Arthaasia Finance is a company engaged in the field of finance, and has problems in making data collection such as the manufacture of stationery demand and in making reports every month still using Microsoft Word and Microsoft Excel. The need for ATK management system is very necessary. Due to the vastness of the management system being run, so the need for management of ATK becomes very important. This system development method refers to the design used in the form of SDLC (Software Development Lift Cycle) in the form of waterfall. Based on the results of research at PT. Arthaasia Finance can be concluded that the Design of Office Stationery Applications At PT. Arthaasia Finance is designed with ease in the process of operation, making it easier for users to access information, facilitate employees in doing the job quickly and efficiently, and facilitate the General Affairs Department staff in viewing data ATK, request data and facilitate in making reports and to reduce errors in recording which is done manually.
\end{abstract}

Keywords: Data, System Report, ATK Request, SDLC, ATK

\begin{abstract}
ABSTRAK
PT. Arthasia Finance merupakan perusahaan yang bergerak di bidang keuangan, dan memiliki permasalahan dalam melakukan pendataan seperti pembuatan permintaan alat tulis kantor maupun dalam pembuatan laporan setiap bulannya masih menggunakan Microsoft word dan Microsoft Excel. Kebutuhan sistem pengelolaan ATK ini sangat diperlukan. Karena luasnya sistem manajemen yang dijalankan, Sehingga kebutuhan manajemen ATK menjadi sangat penting. Metode pengembangan sistem ini mengacu pada perancangan yang digunakan berupa SDLC (Software Development Lift Cycle) berupa waterfall. Berdasarkan hasil penelitian pada PT. Arthaasia Finance dapat disimpulkan bahwa Perancangan Aplikasi Pengolahan ATK Pada PT. Arthaasia Finance dirancang dengan mudah dalam proses pengoperasiannya, sehingga memudahkan pemakai dalam mengakses informasi, mempermudah karyawan dalam melakukan pekerjaan dengan cepat dan efisien, serta memudahkan staff Department General Affairs dalam melihat data ATK, data permintaan dan memudahkan dalam membuat laporan dan untuk mengurangi kesalahan dalam pencatatan yang dilakukan secara manual.
\end{abstract}

Kata Kunci : Data, Laporan System, Permintaan ATK, SDLC, ATK

\section{PENDAHULUAN}

Komputerisasi sistem dalam sebuah perusahaan menjadi hal yang penting, terutama pada perusahaan-perusahaan menengah ke atas yang memiliki sistem cukup kompleks. Pengaturan sistemsistem dalam perusahaan akan menjadi lebih mudah dan cepat dengan sistem komputerisasi, termasuk dalam pengaturan sistem pengadaan alat tulis kantor. Kebutuhan alat tulis kantor yang banyak harus 
diimbangi dengan penyediaan stok alat tulis kantor yang memadai. Keseimbangan ini mungkin dicapai dengan sistem pemantauan yang jelas pada bagian penyediaan alat tulis kantor.

PT. Arthaasia Finance adalah perusahaan dibidang keuangan khususnya pembiayaan. Mengingat akan pentingnya kebutuhan informasi yang sudah terkomputerisasi, Perusahaan tersebut membutuhkan sebuah aplikasi yang dapat dimanfaatkan kegunaaannya untuk keperluan pekerjaan Pengelolahan alat tulis kantor yang dapat mempermudah permintaan alat tulis kantor tersebut. Pada Departmen General Affairs membutuhkan sebuah aplikasi pengolahan alat tulis kantor berbasis web, dikarenakan proses yang berjalan saat ini untuk permintaan atk tersebut dilakukan masih secara manual menggunakan (Microsoft Word dan Microsoft Excel), dalam pembuatan permintaan alat tulis kantor maupun dalam pembuatan laporan setiap bulannya.

\section{METODE PENELITIAN}

\section{Metode Analisa Penelitian}

Berikut ini penggambaran metode analisa pada sistem Alat Tulis Kantor:

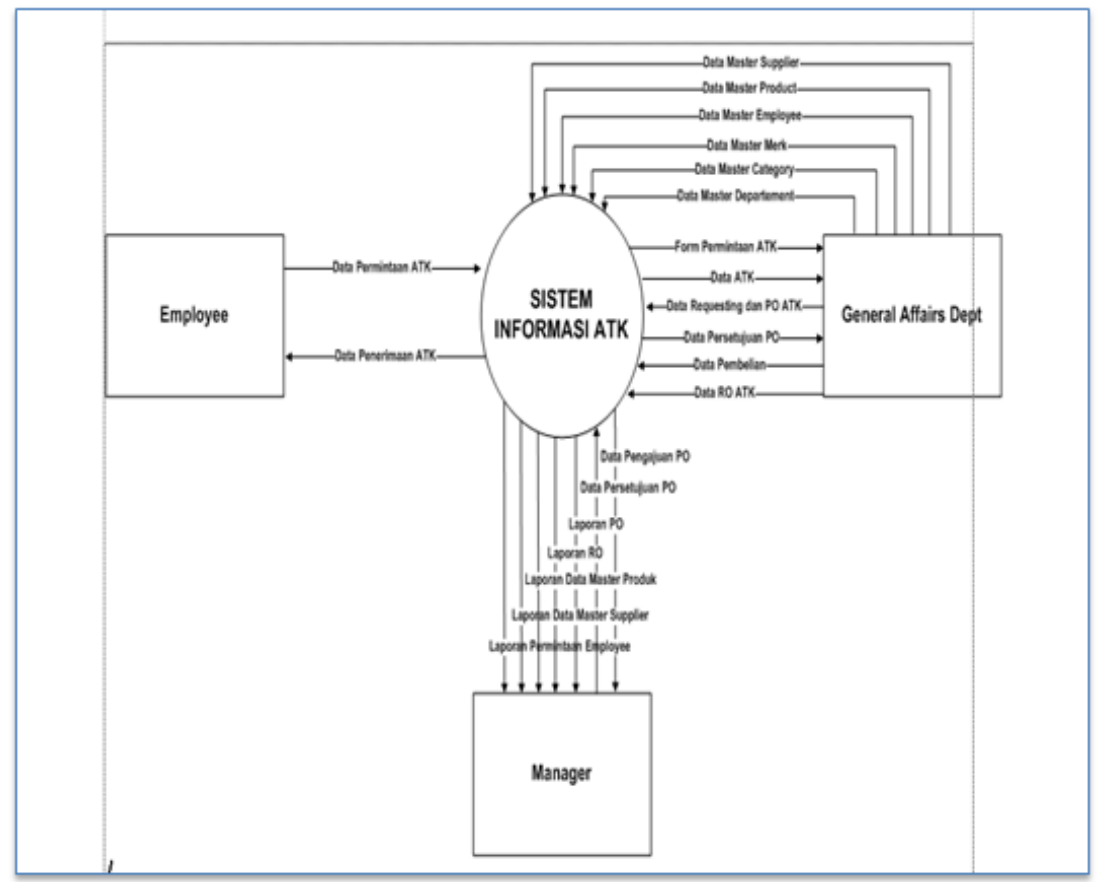

Gambar 1. Metode Analisa Sistem Yang Berjalan

\section{Keterangan :}

1. Menentukan identitas dari sistem yakni menentukan sistem apa yang diterapkan, batasannya dan apa yang dilaksanakan sistem tersebut. Bagaimana bagiaan-bagian yang ada dalam sistem itu saling berhubungan menjadi satu kesatuan

2. Menentukan output yang dihasilkan sistem. Fungsi dan tujuan yang diminta untuk memaksimalkan pengolahan data secara komputerisasi.

3. Bagian-bagian apa saja yang terdapat dalam sistem dan apa tujuan dari masingmasingdan saling berhubungan satu sama dengan yang lain.

\section{Metode Analisa SDLC (System Development life Cycle)}

Metode perancangan yang digunakan adalah metode SDLC (System Development life Cycle) dengan model waterfall. Model ini memberikan pendekatan-pendekatan sistematis dan berurutan bagi pengembangan piranti lunak. Berikut gambar pengembangan sistem perangkat lunak dengan proses SDLC dengan model waterfall: 


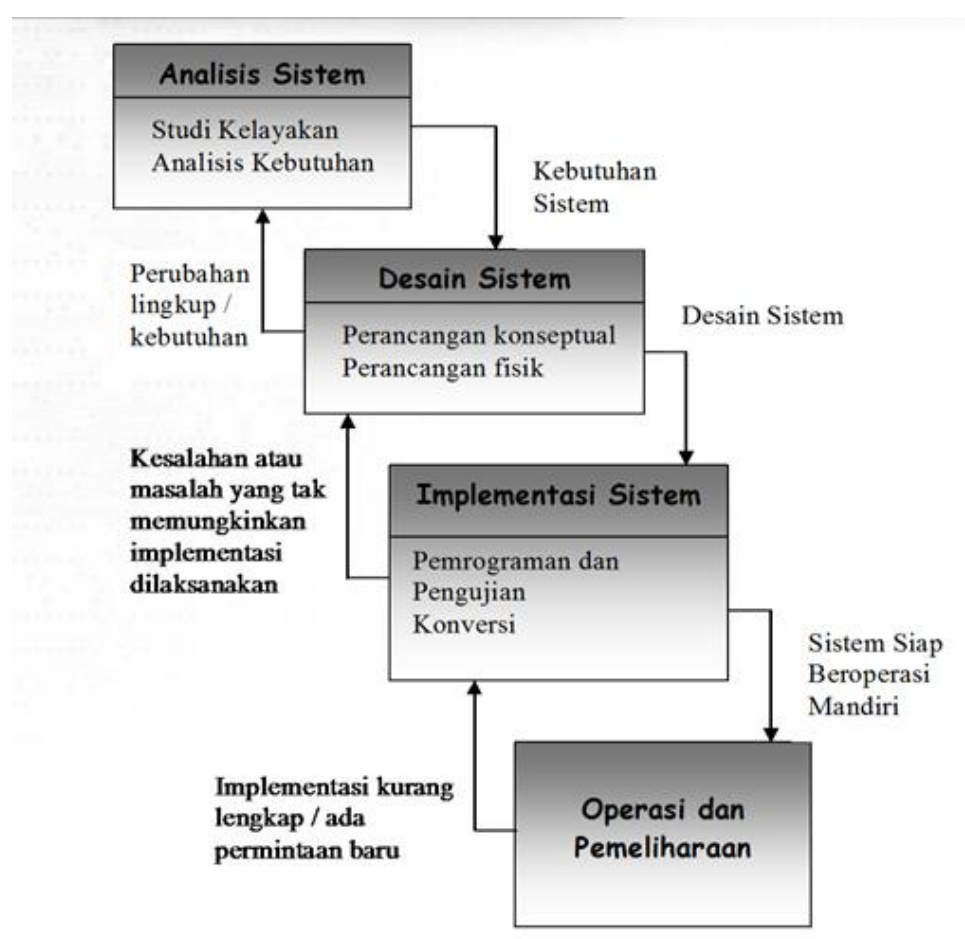

Gambar 2. SDLC model waterfall

Penjelasan dari tahap-tahap waterfall model adalah sebagai berikut:

1. Perancangan Sistem (System Enginering)

Perancangan sistem sangat diperlukan, karena piranti lunak biasanya merupakan bagian dari suatu sistem yang lebih besar. Pembuatan sebuah piranti lunak dapat dimulai dengan melihat dan mencari apa yang dibutuhkan oleh sistem. Dari kebutuhan sistem tersebut akan diterapkan kedalam piranti lunak yang dibuat.

2. Analisa Kebutuhan Piranti Lunak (Software Requirement Analysis)

Merupakan proses pengumpulan kebutuhan piranti lunak. Untuk memahami dasar dari program yang akan dibuat, seorang analisis harus mengetahui ruang lingkup informasi, fungsi-fungsi yang dibutuhkan, kemampuan kinerja yang ingin dihasilkan dan perancangan antar muka pemakai piranti lunak tersebut.

3. Perancangan (Design)

Perancangan piranti lunak merupakan proses bertahap yang memfokuskan pada empat bagian penting, yaitu: struktur data, arsitektur piranti lunak, detil prosedur, dan karakteristik antar muka pemakai.

4. Pengkodean (Coding)

Pengkodean piranti lunak merupakan proses penulisan bahasa program agar piranti lunak tersebut dapat dijalankan oleh mesin.

5. Pengujian (Testing)

Proses ini akan menguji kode program yang telah dibuat dengan memfokuskan pada bagian dalam piranti lunak. Tujuannya untuk memastikan bahwa semua pernyataan telah diuji dan memastikan juga bahwa input yang digunakan akan menghasilkan output yang sesuaif. 
6. Pemeliharaan (Maintenance) Proses ini dilakukan setelah piranti lunak telah digunakan oleh pemakai atau konsumen. Perubahan akan dilakukan jika terdapat kesalahan, oleh karena itu piranti lunak harus disesuaikan lagi untuk menampung perubahan kebutuhan yang diinginkan konsumen.

Berikut ini adalah daftar literature review yang digunakan dalam penelitian ini:

1. Penelitian yang dilakukan oleh Indriani, K. (2015). Sistem Informasi Inventory Alat Tulis Kantor (ATK) menggunakan metode Waterfall (Studi Kasus: Otoritas Jasa Keuangan (OJK)). Jurnal Techno Nusa Mandiri, 12(1), 69-76. Penelitian ini membahas Membuat Sistem Pengelolaan ATK yang dilaksanakan secara manual, terjadi kesalahan informasi dan diharapkan dapat membantu, mempercepat proses pembuatan laporan pemakaian ATK laporan yang dapat di pertanggungjawabkan. Menambah fitur-fitur dan fasilitas yang lebih memudahkan pengguna/user dalam mengolah ini sehingga menjadi salah satu pilihan untuk pengambilan keputusan yang tepat.

2. Penelitian yang dilakukan oleh Nurasiah, N. (2014). System Information Development Plan of Tuition Payment by SDLC Waterfall Method. Jurnal Ilmiah Teknologi dan Rekayasa, 19(3). Penelitian ini membahas mengembangkan sistem informasi pembayaran uang kuliah yang sedang berjalan dengan metode waterfall, Sistem yang telah terintegrasi dengan bagian akademik dan bersifat online dapat membuat sistem menjadi lebih efisien dan efektif sehingga menghasilkan informasi yang akurat mahasiswa yang membutuhkan. Sistem yang efisien akan menciptakan kenyamanan sehingga dapat meningkatkan mutu pelayanan.

3. Penelitian yang dilakukan oleh Cahyaningtyas, R., \& Iriyani, S. (2014). Perancangan Sistem Informasi Perpustakaan Pada Smp Negeri 3 Tulakan, Kecamatan Tulakan Kabupaten Pacitan. IJNS-Indonesian Journal on Networking and Security, 4(2). penelitian ini membahas tentang Proses pencatatan peminjaman dan pengembalian buku masih menggunakan cara manual dan mencakup: Pencatatan Anggota, Pencatatan Peminjaman dan Pengembalian Buku serta Pembuatan laporan bulanan.

4. Penelitian yang dilakukan oleh Rahayu, S., \& Nurhaeni, T. (2015). Sistem persediaan alat tulis kantor sebagai penunjang pengambilan keputusan bagian logistik di perguruan tinggi raharja. CCIT Journal, 8(2), 91-101. Pelitian ini membahas tentang memberikan pelayanan informasi yang akurat, tepat waktu dan sesuai dengan kebutuhan yang diinginkan oleh staff yang belum menghasilkan laporan yang efisien karena belum tersimpan dalam database server sehingga pekerjaan dilakukan berulang-ulang. Selain itu, kemudahan lainnya adalah dalam memenuhi permintaan barang setiap divisi perguruan tinggi raharja dapat direalisasikan karena stok barang tersedia.

5. Penelitian yang dilakukan oleh Nugraha, D. W. (2013). Membangun Sistem Informasi Pengelolaan Alat Tulis Kantor (ATK) Berbasis WEB. MEKTEK, 14(2). Penelitian ini membahas tentang membangunan sistem informasi pengelolaan ATK berbasis web yang masih dilakukan secara manual.

Setelah melakukan peninjauan dari 4 Literature Review yang ada, telah banyak penelitian mengenai sistem yang berhubungan dengan metode mengelola Alat Tulis Kantor dan perancangan SDLC (Software Development Lift Cycle) yang bertujuan untuk membuat secara efisien, data yang valid, dan mempercepat proses pendataan atau pengolahan barang.

\section{HASIL DAN PEMBAHASAN}

\section{Permasalahan Yang Dihadapi}

1. Sistem yang berjalan saat ini sulit untuk mendapatkan informasi ATK secara update, dikarenakan proses masih dilakukan secara manual

2. Dalam kegiatan operasional inventory barang ATK masih sering terjadi human error seperti kesalahan pencatatan yang menyebabkan data tidak valid.

3. Laporan belum optimal sehingga sering terjadi keterlambatan dalam menghasilkan laporan. 


\section{Alternatif Pemecahan Masalah}

Alternatif pemecahan masalahnya adalah sebagai berikut:

1. Membuatkan sistem laporan yang optimal agar tidak terjadi lagi keterlambatan dalam pembuatan laporan.

2. Membuatkan sistem operasional barang ATK agar dapat meminimalkan human error dan memberikan kemudahan dalam kegiatan operasional ATK sehingga menjadi cepat, tepat dan akurat.

3. Membuatkan sistem yang dapat menunjang barang ATK dengan menyediakan order barang secara baik dan dapat melihat stok barang ATK secara update.

\section{Perancangan Prototype}

A. Tampilan Login Admin

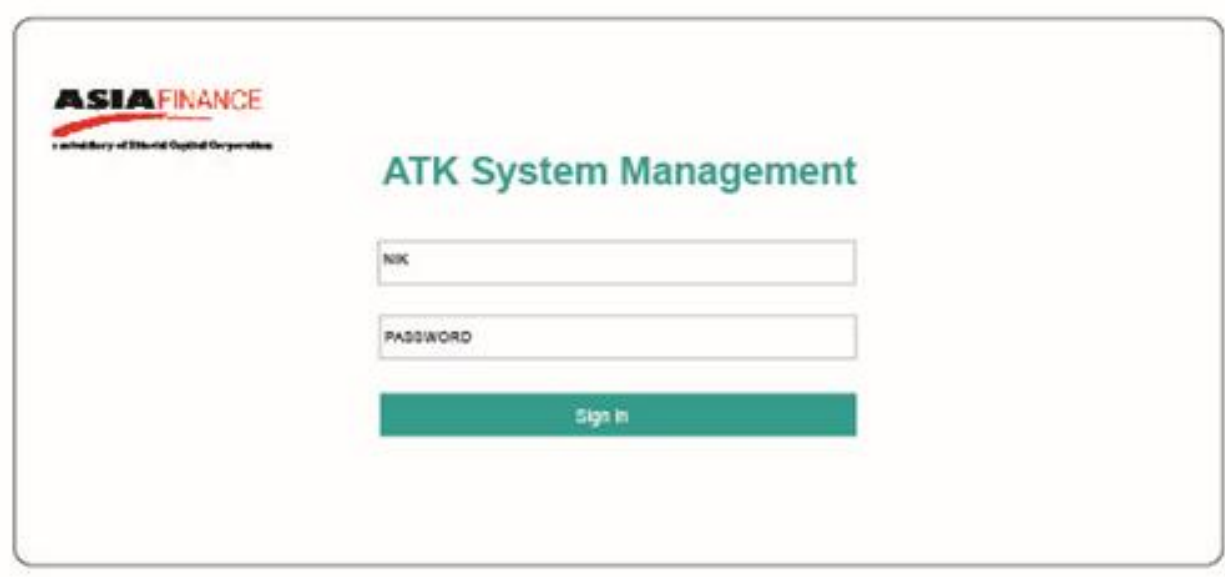

Gambar 3. Tampilan login admin

Gambar 3 adalah tampilan antar muka login untuk admin yang mana sebelum masuk ke menu utama aplikasi admin diharuskan untuk login terlebih dahulu dengan memasukkan NIK dan password.

B. Tampilan Menu Utama

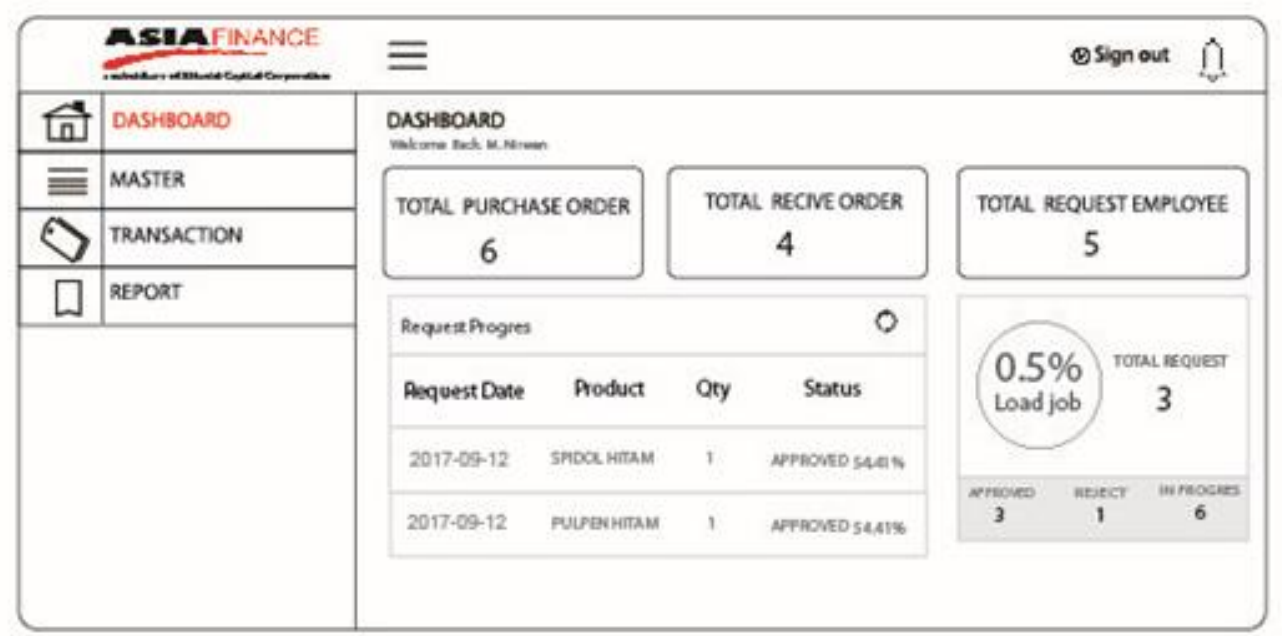

Gambar 4. Tampilan Menu Utama

Gambar 4 adalah tampilan menu utama aplikasi, setelah user memasukkan NIK dan password yang terdaftar dalam database maka secara otomatis user akan langsung dihadapkan pada menu utama, dimana user dapat memilih menu sesuai kebutuhan. Pada tampilan menu utama terdapat menu dashboard, master, transaction, dan report. Fungsi tampilan menu dashboard adalah memberian 
informasi kepada admin mengenai total purchase order, receive order, total request employee, serta status permintaan barang.

C. Tampilan Menu Master

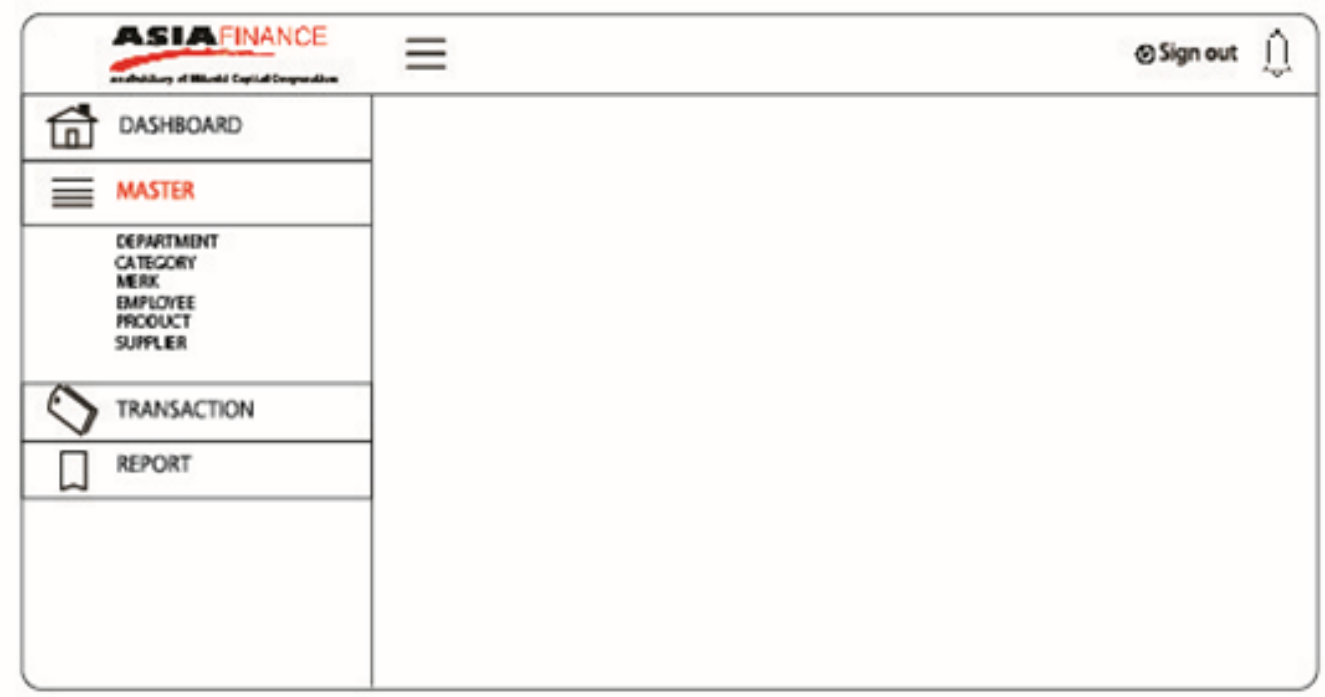

Gambar 5. Tampilan Menu Master

Gambar 5. adalah tampilan menu master yang digunakan untuk membuat permintaan barang. Dalam menu master terdapat sub menu deparment yang digunakan untuk menginput dan menyimpan data department., category merupakan form untuk menginput dan menyimpan data kategori barang yang akan di order, merk merupakan form untuk menginput dan menyimpan data merk barang yang akan di order, employee yang digunakan untuk menginput dan menyimpan data karyawan yang mengajukan pengajuan barang yang akan memberikan informasi NIK, nama, dan department user yang mengajukan barang, product yang digunakan untuk menginput dan menyimpan data produk barang yang akan di order. User harus mengisi nama, kategori, dan merk barang yang akan di order, dan supplier yang digunakan untuk menginput dan menyimpan data supplier yang akan menerima permintaan pembelian dari PT. Arthaasia Finance.

D. Tampilan Menu Transaction

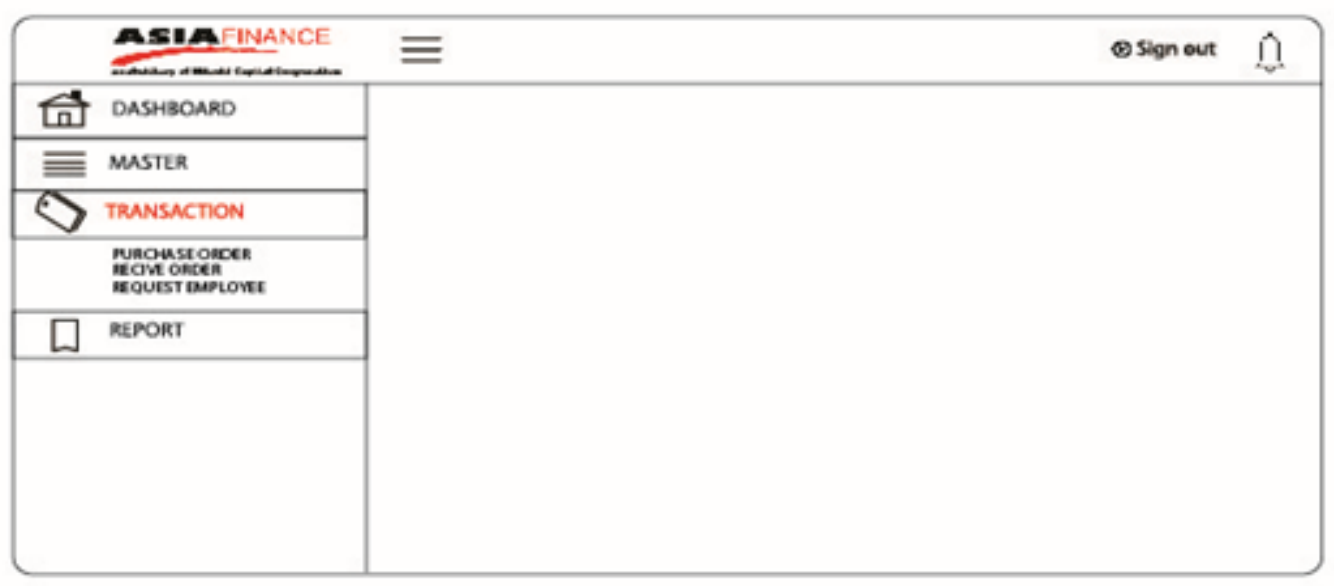

Gambar 6. Tampilan Menu Transaction

Gambar 6. adalah tampilan menu transaction yang digunakan untuk menginputan dan pembelian barang kepada supplier. Menu master terdiri dari sub master yaitu purchase order merupakan data yang dikirimkan kepada supplier untuk pembelian barang, receive order yang 
digunakan untuk menginput dan menyimpan data barang yang telah masuk setelah proses pembelian,, maka hasilnya akan secara otomatis masuk kedalam report, dan request employee terbagi menjadi 2 admin dan user.

E. Tampilan Menu Report Master

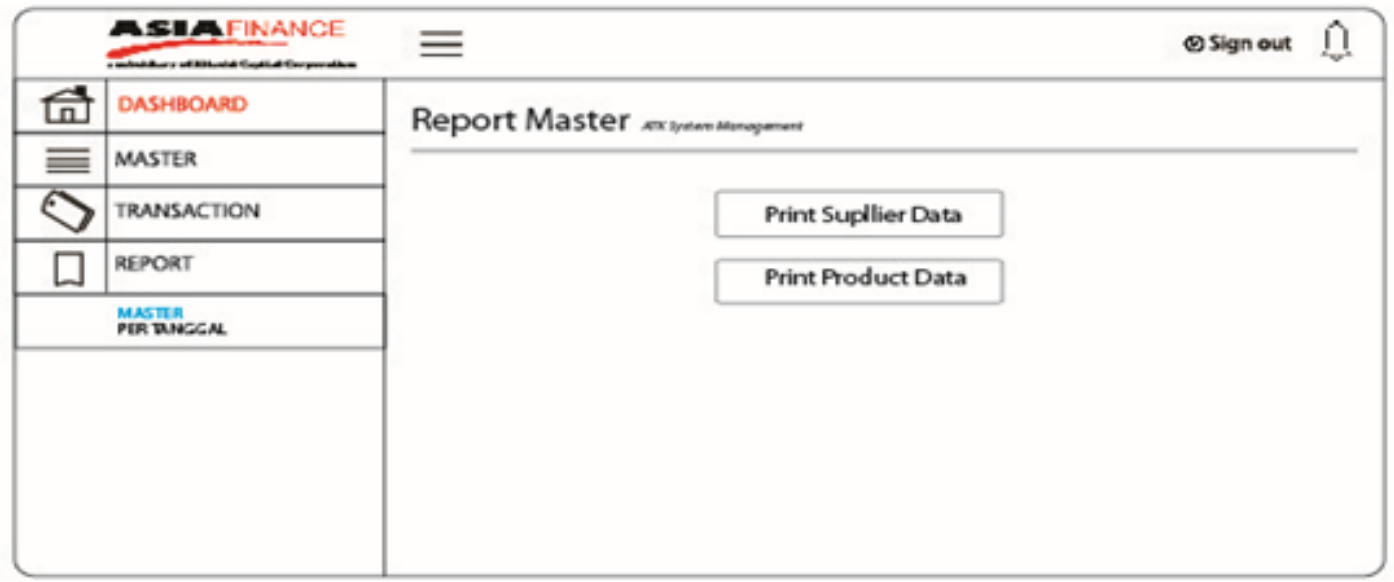

Gambar 7. Tampilan Menu Report

Gambar 7. adalah tampilan menu report yang digunakan untuk membuat laporan. Informasi mengenai data supplier dan produk sudah tersimpan di menu report master ini. Terdiri dari report pertanggal yang digunakan untuk membuat laporan sehingga admin dapat memilih periode laporan sesuai dengan kebutuhan.

\section{Implementasi}

Berdasarkan hasil pengujian dapat ditarik kesimpulan bahwa perangkat lunak dapat mengetahui fungsi - fungsi yang tidak benar atau hilang, kesalahan interface, kesalahan dalam struktur data atau akses database eksternal, kesalahan kinerja, inisialisasi, kesalahan terminasi dan secara fungsional mengeluarkan hasil yang sesuai dengan yang diharapkan.

berikut tampilan menu yang sudah di implementasi.

\section{A. Tampilan Login Admin}

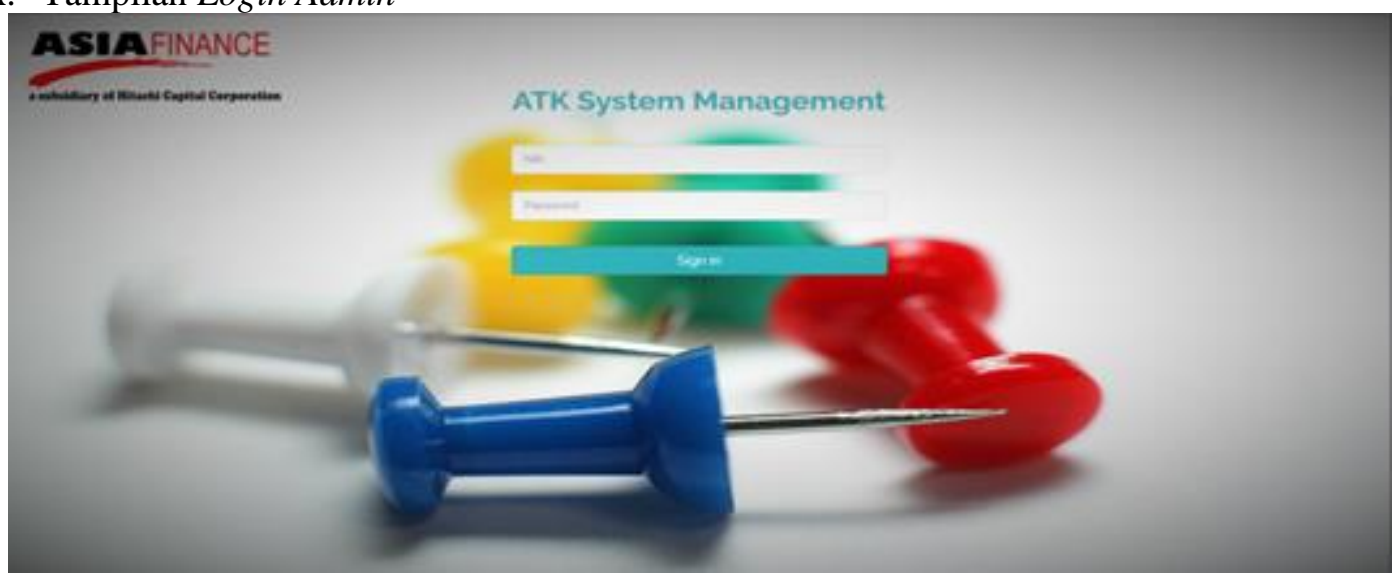

Gambar 8. Tampilan Login Admin 


\section{B. Tampilan Menu Dashboard}

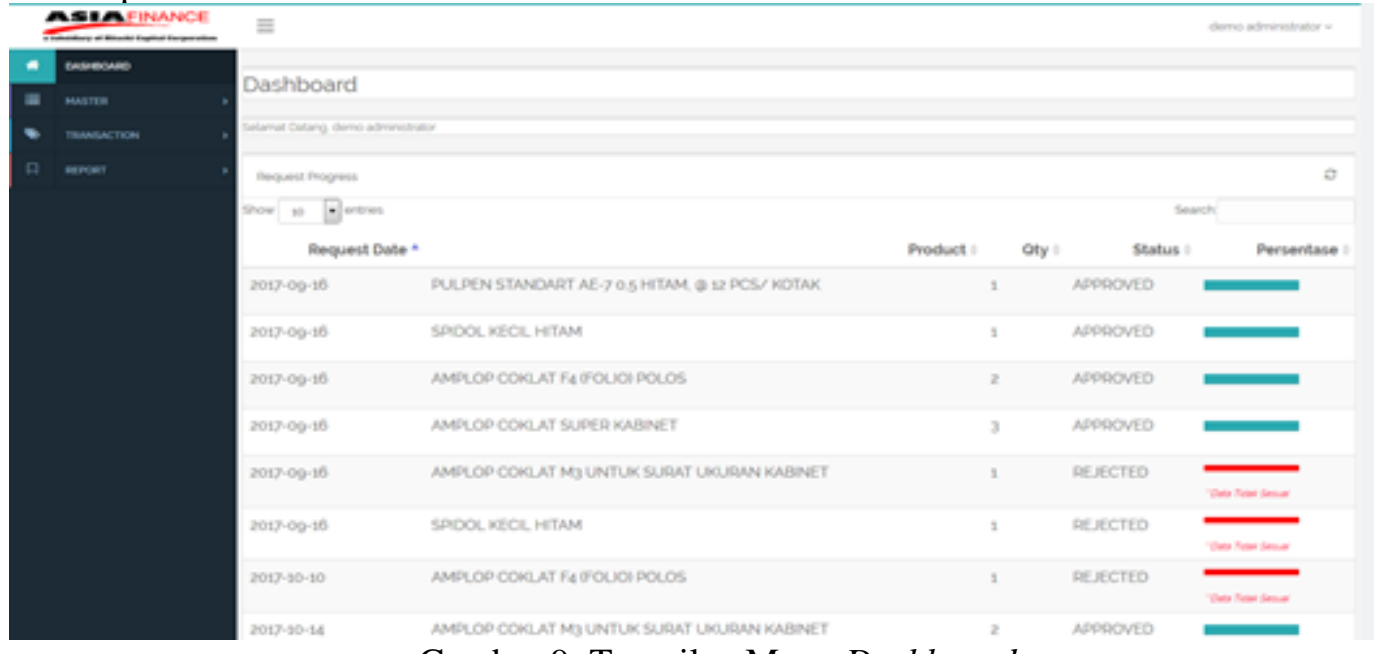

Gambar 9. Tampilan Menu Dashboard

\section{Tampilan Menu Department}

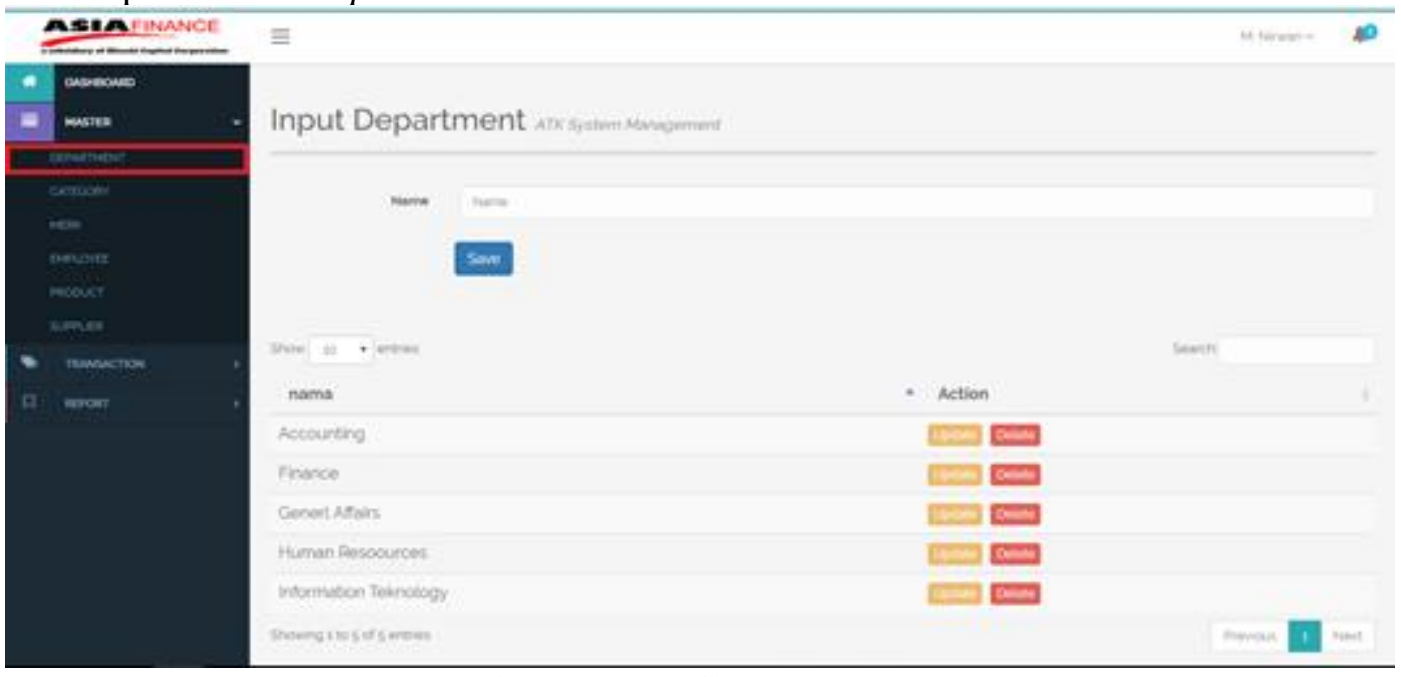

Gambar 10. Tampilan Menu Department

D. Tampilan Menu Transaction

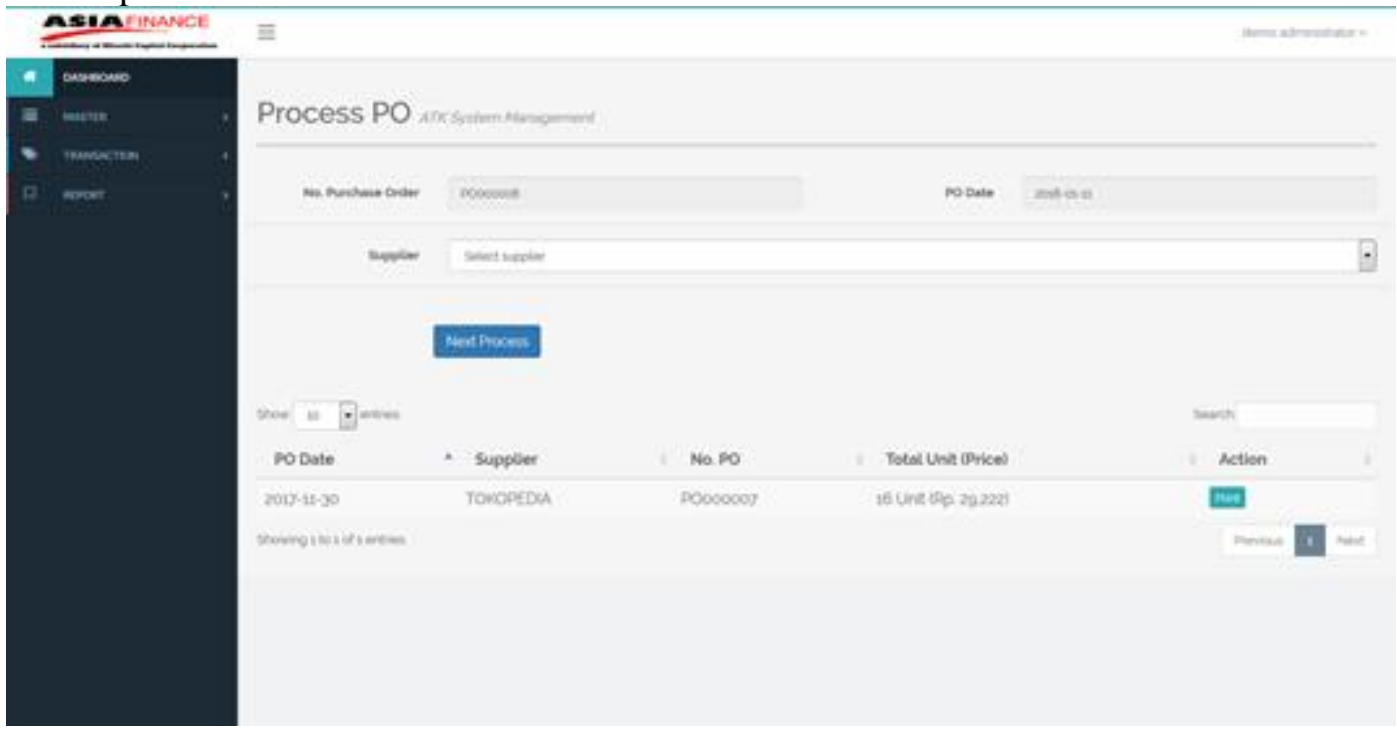

Gambar 11. Tampilan Menu Transaction 
E. Tampilan Menu Report Master

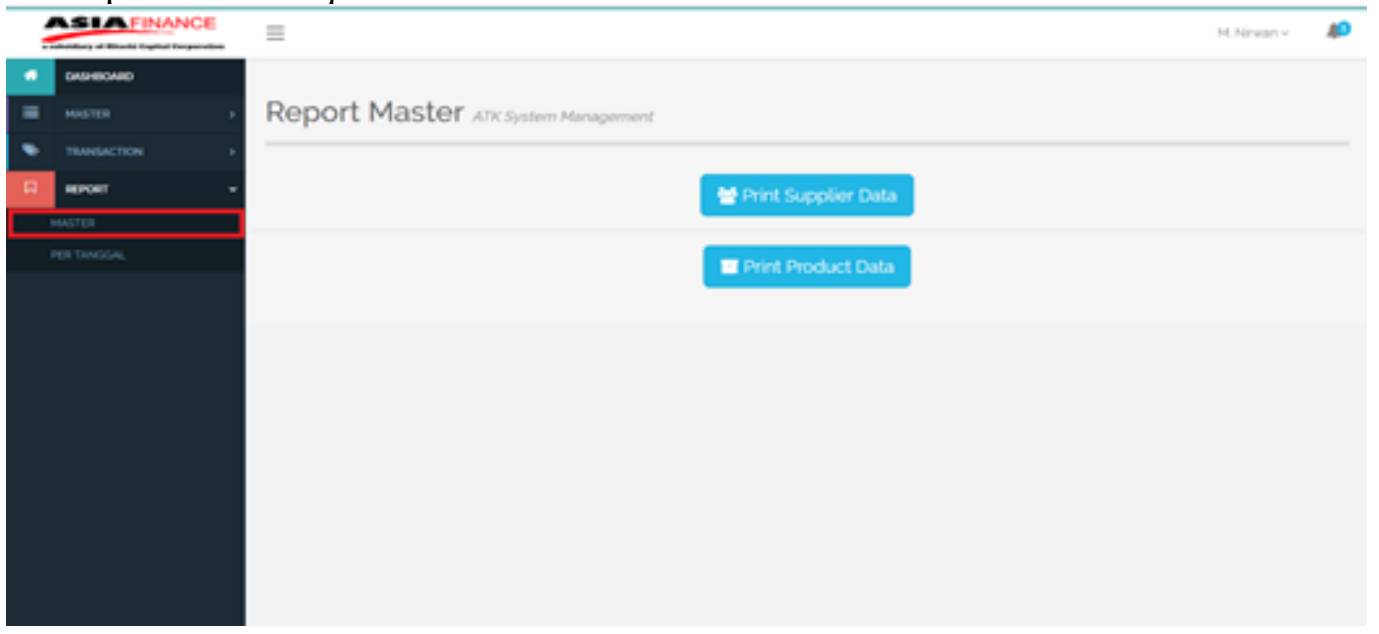

Gambar 12. Tampilan Menu Report Master

F. Tampilan Laporan Supplier

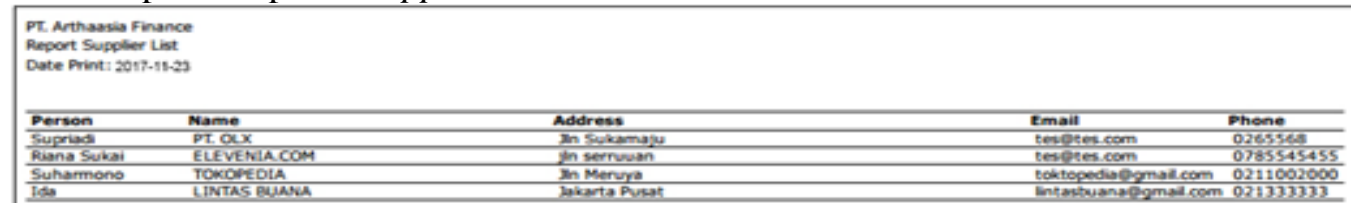

Gambar 13. Tampilan Laporan Supplier

Gambar 13. Tampilan laporan supplier digunakan untuk menyediakan informasi mengenai data supplier ATK.

G. Tampilan Laporan Product Data

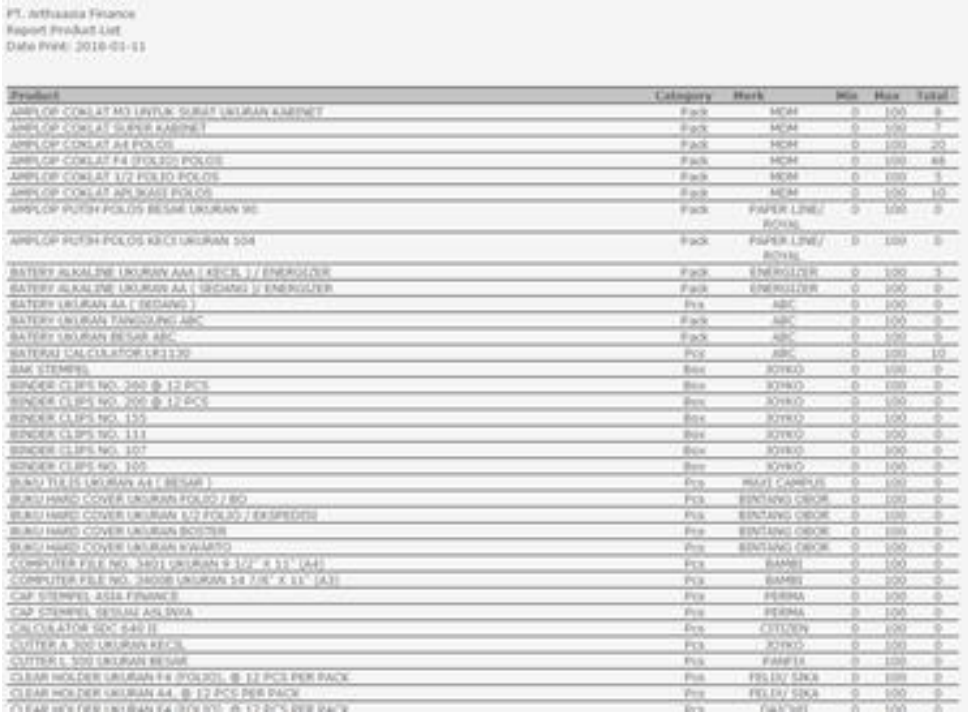

Gambar 14. Tampilan Laporan Product Data 
Gambar 14. adalah tampilan laporan product data digunakan untuk menyediakan informasi mengenai data master barang.

H. Tampilan Laporan Receive Order

\begin{tabular}{|c|c|c|c|c|}
\hline \multicolumn{5}{|c|}{$\begin{array}{l}\text { F. Arthassia Finance } \\
\text { Report Receive Order } \\
\text { Date Aeriode: 2016-09-01 To 2016-09-21 }\end{array}$} \\
\hline No & Supplier & Product & Qty & Price \\
\hline$\overline{R 0000001}$ & ptox & NMALOP COKLAT MU UNTUK SURAT UKURAN KABINET & 5 & $\begin{array}{l}k a \\
10,000\end{array}$ \\
\hline$\frac{\bar{R} 0000001}{R 0000001}$ & $\frac{\text { P. OX }}{\text { P. Ox }}$ & 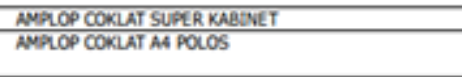 & $\frac{10}{10}$ & $\begin{array}{l}\frac{k_{9}, 2,500}{16} \\
25,000\end{array}$ \\
\hline$\overline{R 0000001}$ & ptox & ANGOP COKLAT F4 (FOUO) POLOS & 50 & $\frac{15000}{35,000}$ \\
\hline$\overline{R 0000002}$ & ELEVENEACOM & ANGLOP COKLAT $1 / 2$ FOLO POLOS & 5 & ${ }_{123456}$ \\
\hline$\overline{\pi 0000003}$ & TOKOFEDIA & PULPEN STANDMRT AE $=7$ 0,5 HITAM, 012 PCS/ KOTAK & 5 & ${ }_{100000}$ \\
\hline R00000004 & ELEVENECOCM & SPIDOL KECTL HITAM & 5 & 150,000 \\
\hline R00000005 & LINESS BUNA & TINTA STAMFLL BESUR RTIAM & 10 & 20,000 \\
\hline
\end{tabular}

Gambar 15. Tampilan Laporan Receive Order

Gambar 15. adalah tampilan laporan receive order digunakan untuk menyediakan informasi mengenai data penerimaan barang ATK.

\section{KESIMPULAN}

Berdasarkan hasil perancangan, analisa, hingga implementasi, dan pengujian aplikasi pada rancangan aplikasi pengolahan alat tulis kantor (ATK) pada PT.Arthaasia Finance maka penulis dapat memberikan kesimpulan sebagai berikut:

1. Rancangan aplikasi pengolahan alat tulis kantor (ATK) pada PT. Arthaasia Finance berbasis web ini, dapat mempermudah dan mempercepat pencatatan pengolahan ATK sehingga proses administrasinya bisa menjadi lebih baik dari sebelumnya. Pencatatan dan pengolahan ini meliputi data permintaan, data pembelian dan data penerimaan.

2. Kerjasama yang terjalin untuk pengadaan alat tulis kantor menjadi lebih mudah karena dapat dikontrol menggunakan sistem sehingga permintan dan laporan yang dihasilkan sistem yaitu laporan stok, laporan permintaan, laporan pembelian ke supplier dan laporan penerimaan baik dari perusahaan.

3. Rancangan sistem ini memiliki fasilitas-fasilitas antara lain menu login untuk pengguna admin, menu dashbord, menu master, menu transection, dan menu report.

\section{SARAN}

Berdasarkan hasil perancangan, analisis, hingga implementasi, dan pengujian maka saran yang diberikan pada penelitian ini sebagai berikut:

1. Untuk pengembangan lebih lanjut, maka dibutuhkan server untuk mengelola database, dan dikembangkan menjadi sistem informasi secara online sehingga dapat di akses oleh semua karyawan yang menggunakan.

2. Laporan yang dihasilkan sitem ini, diharapkan kedepannya dikembangkan agar ada penyaringan berdasarkan nama maupun departemen yang request.

3. Pengguna sistem ini khususnya admin perlu melakukan backup data sehingga dapat meminimalisir kehilangan data akibat hal yang tidak diinginkan. 


\section{UCAPAN TERIMA KASIH}

Penulis mengucapkan terima kasih kepada PT. Arthaasia Finance Jakarta, STMIK Raharja Tangerang, dan Dosen Pembimbing yang telah memberi dukungan penuh terhadap penelitian ini.

\section{DAFTAR PUSTAKA}

1. Rahayu, S., \& Nurhaeni, T. (2015). Sistem Persediaan Alat Tulis Kantor Sebagai Penunjang Pengambilan Keputusan Bagian Logistik di Perguruan Tinggi Raharja. CCIT Journal, 8(2), 91-101.

2. Cahyaningtyas R dan Iriani S. 2015. Perancangan Sistem Informasi Perpustakaan Pada Smp Negri 3 Tulakan, Kecamatan Tulakan Kabupaten Pacitan, IJNS-Indonesia Jurnal On Networking And Security Vol. 4. 2302-5700.

3. Indriani, Karlena dan Sudarmadi. 2015. Sistem Informasi Inventory Alat Tuis Kantor (ATK) Menggunakan Metode Waterfall. Jurnal Techno Nusa Mandiri. Vol.12, No.1.

4. Nurasiah, N. (2014). System Information Development Plan of Tuition Payment by SDLC Waterfall Method. Jurnal Ilmiah Teknologi dan Rekayasa, 19(3).

5. Nugraha, D. W. (2013). Membangun Sistem Informasi Pengelolaan Alat Tulis Kantor (ATK) Berbasis WEB. MEKTEK, 14(2). 